\title{
The clinical impact of incidental sellar uptake on F-18 FDG PET/CT
}

\author{
Zehra Pınar Koç*,1, Pelin Özcan Kara' ${ }^{*}$, Emel Sezer ${ }^{2}$, Kadir Eser² \& Anıl Özgür ${ }^{3}$ \\ ${ }^{1}$ Department of Nuclear Medicine, Mersin University Medical Faculty, Mersin, Turkey \\ ${ }^{2}$ Department of Oncology, Mersin University Medical Faculty, 33343, Mersin, Turkey \\ ${ }^{3}$ Department of Radiology, Mersin University Medical Faculty, Mersin, Turkey \\ *Author for correspondence: Tel.: +90 32424100002 2524; Fax: +90 324241 0098; zehrapinarkoc@gmail.com
}

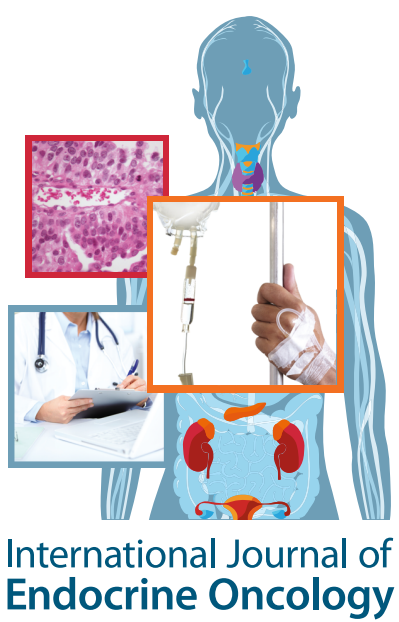

\begin{abstract}
Aim: The most frequent finding associated with incidental fluorodeoxyglucose (FDG) uptake in sellar region in oncologic F-18 FDG PET/CT is adenoma. However, reports of metastatic involvement exist. We investigated the clinical significance of incidental FDG uptake in this region. Materials \& method: 34 patients with several primary tumors who were referred for staging, restaging or treatment response via F-18 FDG PET/CT were included. Images were reviewed and patients with significant FDG uptake in the sellar region were referred. Results: Mean lesion diameter was $11.9 \pm 4.9 \mathrm{~mm}$ and mean standardized uptake value was $8.2 \pm 6$.1. Thirteen patients underwent MRI, and the others underwent follow-up F-18 FDG PET/CT. MRI revealed metastatic involvement in nine patients and macro- or micro-adenoma in four. Metastatic patients also had other lesions, yet management did not change. Conclusion: FDG accumulation in the sellar region might be associated with metastasis or adenoma. However, it did not change management. Future studies are warranted.
\end{abstract}

First draft submitted: 2 October 2018; Accepted for publication: 16 January 2019; Published online: 3 September 2019

Keywords: adenoma $\bullet$ FDG $\bullet$ hyphophysis $\bullet$ metastasis

The increase in the number of the positron emission tomography-computed tomography (PET/CT) devices worldwide has resulted in an increase in the number of incidental findings. Pituitary uptake is an incidental finding in the F-18 FDG PET/CT examinations. A previous study reported an incidence of $0.8 \%$ and showed that this finding was frequently associated with the incidental pituitary adenoma (89.7\%) [1]. Since incidental pituitary adenomas have high prevalence in the general population (16.7\%), incidental detection is an expected outcome [2]. Additional prior investigations have shown that macro- or micro-adenomas might show high FDG uptake [3,4]. However, there are also case reports showing that pituitary involvement of primary malignant tumors might present as pituitary uptake [5]. In the series of Jeong et al., any of the patients had metastatic involvement among the patients with FDG uptake in the sellar region [6], but this issue has to be evaluated. The aim of this study was to investigate the reasons for the incidental FDG uptake detected in oncologic PET/CT studies and the clinical significance of this finding.

\section{Materials \& methods}

Patients

Patients diagnosed with primary tumors (lung, $\mathrm{n}=7$; primary unknown, $\mathrm{n}=5$; breast, $\mathrm{n}=4$; lymphoma, $\mathrm{n}=3$; stomach, $\mathrm{n}=2$; pleura, $\mathrm{n}=2$; mediastinum, $\mathrm{n}=2$; thyroid, $\mathrm{n}=2$; hepatocelular carcinoma, renal, esophagus, colon, multiple myeloma, malign melanoma, brain) who attended the Nuclear Medicine Department for staging $(\mathrm{n}=14)$, restaging $(n=6)$, treatment response evaluation $(n=7)$ or primary site investigation $(n=7)$ between March 2016 and March 2018 were included in the study. The F-18 FDG PET/CT images of 34 patients (18M, 16F; mean: $64.4 \pm 16.2$ years old) were analyzed regarding the standardized uptake value (SUVmax) and dimensions of the lesion (if measurable), primary diagnosis, MRI, follow-up PET/CT results and these were decided regarding the metastatic/non-metastatic involvement of the sellar region. 
Table 1. Clinical features of the subjects included in the study.

\begin{tabular}{|lll|}
\hline Clinical features & Distribution & \\
\hline Female/male & $16 / 18$ & \\
\hline Age & $64.4 \pm 16.2$ years & 29 certain primary tumors \\
\hline Malignancy & 5 primary unknown & Uptake: $8.2 \pm 6.1$ \\
\hline Lesion characteristics & $11.9 \pm 4.9 \mathrm{~mm}$ & four adenoma \\
\hline Lesion results & nine metastasis & \\
\hline
\end{tabular}

The local ethics committee approved the study and informed consents of the patients for the imaging procedure were obtained.

\section{Imaging procedure}

All of the patients underwent F-18 FDG PET/CT examination after $>6 \mathrm{~h}$ fasting and restriction of physical effort at least $24 \mathrm{~h}$ prior to the imaging study. The radiopharmaceutical injection was performed (mean $370 \mathrm{MBq}$ $/ 10 \mathrm{mCi} /$ adjusted according to the bodyweight) to each patient from a venous line $60 \mathrm{~min}$ before the imaging began. The imaging was performed by PET/CT scanner (Discovery PET/CT 610, GE, MA, USA) with additional low dose CT scan $(130 \mathrm{kV}, 50 \mathrm{mAs}$, a pitch of 1.5 , a thickness of $5 \mathrm{~mm}$, in $70 \mathrm{~cm}$ field of view) in order to provide the attenuation correction with oral contrast administration from the skull base to the upper thigh with the acquisition time of $1 \mathrm{~min}$ per bed position.

\section{MRI examination}

All pituitary MRI examinations were performed at 1.5 T-unit (Signa Excite, GE Medical Systems, WI, USA) with standard protocol including coronal T2-weighted images and contrast enhanced dynamic coronal T1 weighted images (slice thickness $3 \mathrm{~mm}$ ).

\section{Results}

Of the patients included in the study, six had no additional metastatic uptake elsewhere in the body. The metastatic sites of the other patients $(\mathrm{N}=28)$ were mediasten lymph node $(\mathrm{n}=11)$, bone $(\mathrm{n}=12)$, abdomen $(\mathrm{n}=5)$, liver $(n=6)$, lung $(n=5)$, pleura $(n=3)$, adrenal $(n=4)$, cervical $(n=6)$ and brain $(n=2)$ region according to the $\mathrm{PET} / \mathrm{CT}$ results.

The mean dimension of the lesions in the sellar region was $11.9 \pm 4.9 \mathrm{~mm}$ in length and the SUVmax of these lesions had a mean of $8.2 \pm 6.1$. The MRI study was performed on 13 patients in this series and results were conclusive of pituitary adenoma in 4 patients (Figures $1 \& 2$ ). Metastatic involvement of the other structures of sella and hypophysis was determined in nine of the patients (mean SUVmax $=9.3 \pm 3.6$ ) (Figure $3 \&$ Table 1). All of the patients with metastatic sellar involvement also had other metastatic lesions elsewhere in the body. Six patients died during the disease course and three of these had pituitary macro or micro adenomas (mean SUVmax $=7.7 \pm 7.5$ ).

The patients without MR results were evaluated in the follow-up ${ }^{18} \mathrm{~F}$ FDG PET/CT results.

\section{Discussion}

Observation of incidental FDG uptake in the sellar region might be related to the pituitary adenoma; however, there are several additional reasons for this finding. Involvement of a rare disease including Erdheim-Chester Disease [7], Langerhans cell histiocytosis and hypophysitis [8] and, rarely, metastasis [9] has previously been reported in the literature. The pituitary gland is not a common site for metastatic involvement [10].

A recent study about the diagnostic performance of F-18 FDG PET/CT and MR in the detection of pituitary adenoma demonstrated that PET/CT may be positive in $80 \%$ of the patients; additionally, PET/CT might show lesions that are not present in the MR of the patients with Cushing syndrome [3,11]. The normal pituitary gland does not show increased metabolic activity in the FDG PET/CT [12]. It is likely that the patients in this study group without significant MR findings were the patients with FDG accumulation in the normal pituitary gland, a rare phenomenon that has also been previously reported [13].

There are some case reports in the literature that show various cancer metastases presented as incidental pituitary uptake in PET/CT studies including endometrium carcinoma [14] and head and neck adenoid cystic carcinoma [1517]. The distant metastasis from a known primary to the sellar region (bone, pituitary) might be more frequent than 


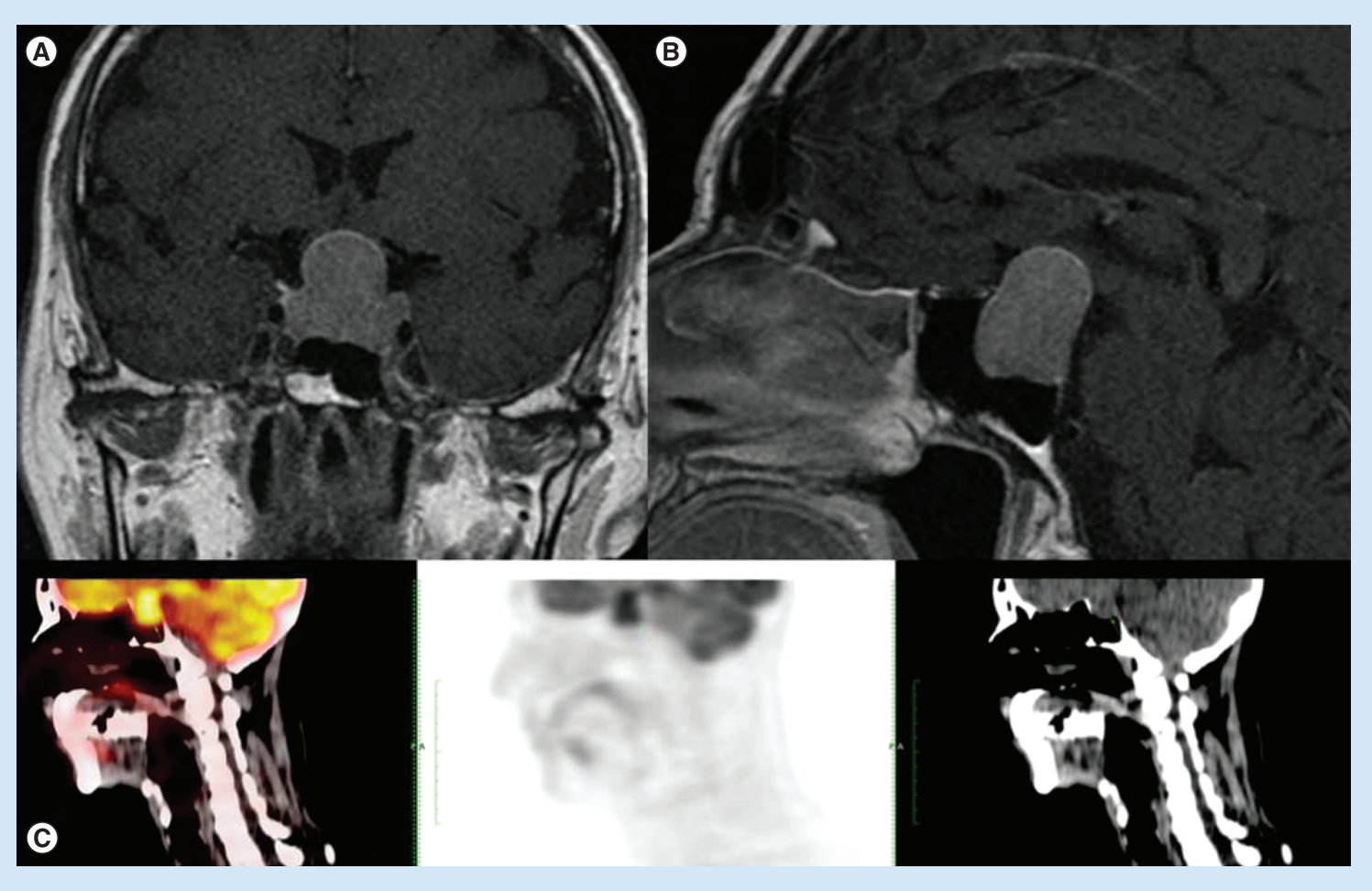

Figure 1. F-18 fluorodeoxyglucose positron emission tomography-computed tomography and magnetic resonance imaging of the sellar lesion. (A) Coronal and (B) sagittal contrast-enhanced T1-weighted images show sellar mass with suprasellar extension. Note the presence of sellar expansion with no separate identifiable pituitary gland. (C) Sagittal projection fusion, positron emission tomography and computed tomography images the hypermetabolic lesion (Standardized uptake value $=10.9$ ) in the hypophysis.

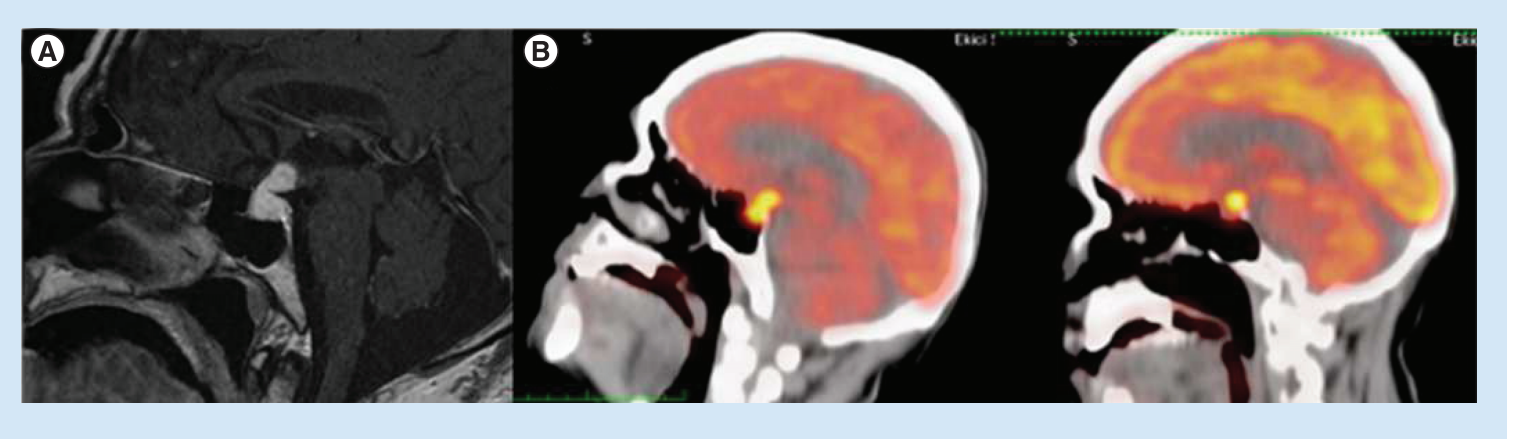

Figure 2. Magnetic resonance and positron emission tomography-computed tomography fusion images of the lesion. (A) Sagittal contrast-enhanced T1-weighted image demostrates pituitary mass with an enlarged uniformly enhancing infundibulum. (B \& C) Sagittal corresponding fusion positron emission tomography-computed tomography images of one year follow-up of the sellar hypermetabolic lesion (Standardized uptake value $=10.5$ ) and the patients died in one month follow-up.

expected. In this series, the ratio of metastatic patients (10:34) was significantly higher than previous reports [13]. The percentage of the pituitary adenomas was only $(47.4 \%)$ in the same study and was lower in this present study (11.8\%) [13]. Additionally, in that series, all the patients with metastatic lesions had diabetes insipidus, something that was not observed in this study. 


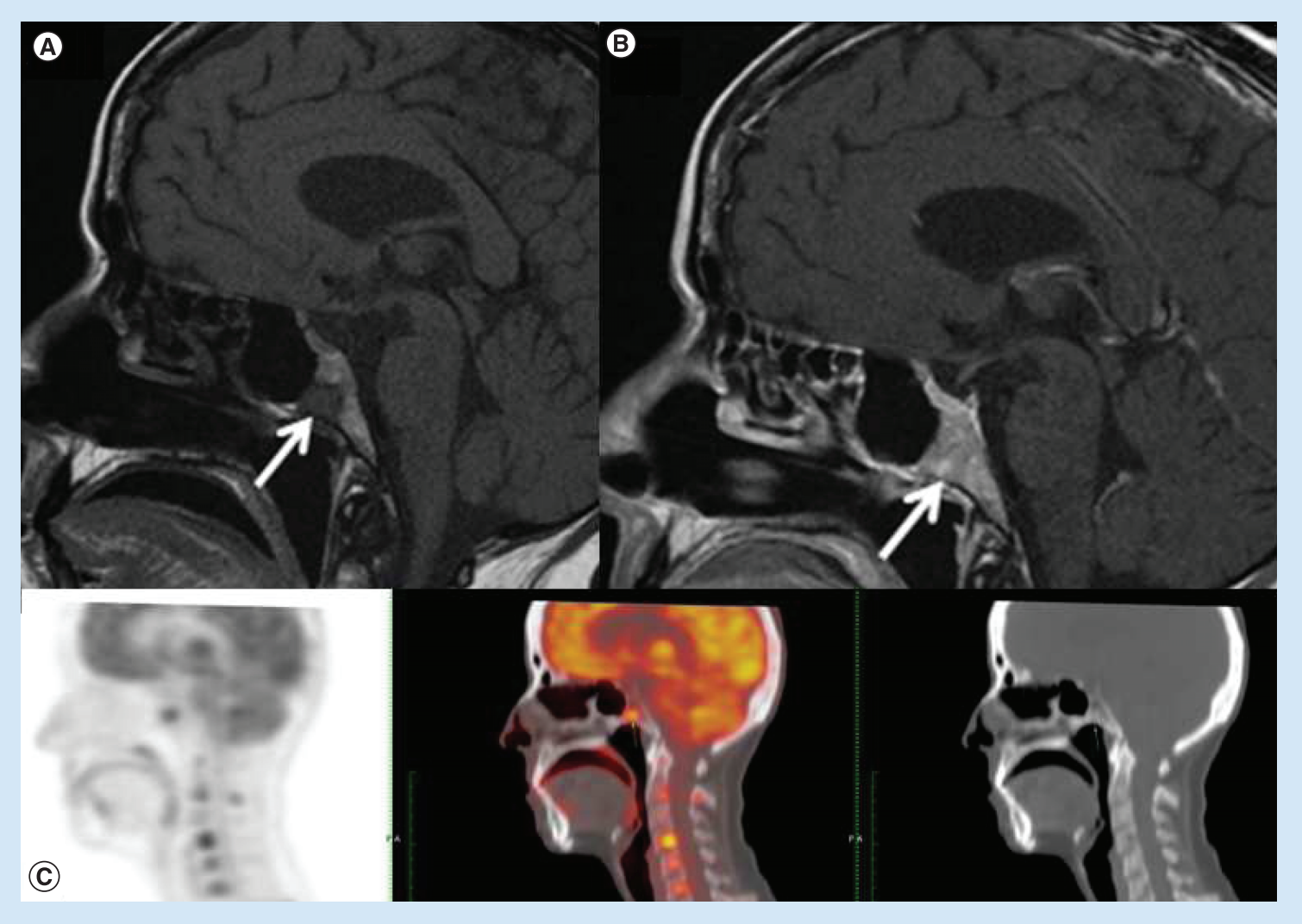

Figure 3. Positron emission tomography, computed tomography and fusion images in comparison with magnetic resonance images of the patient. (A) Sagittal precontrast T1-weighted image shows a hypointense lesion (arrow) in the clivus. (B) Sagittal postcontrast T1-weighted image demonstrates homogeneous enhancement (arrow) within the lesion. (C) Corresponding sagittal projection positron emission tomography, fusion and computed tomography images of the same lesion with increased fluorodeoxyglucose uptake (Standardized uptake value $=6.8$ ).

There are other radiopharmaceuticals that might accumulate in the adenoma of pituitary gland as well. One case report reported both F-18 FDG and F-18-choline accumulation in the pituitary adenoma [18]. Additionally, there is a case report of the functioning pituitary adenoma shown by C-11 methionine PET/CT [19].

A recent study has demonstrated higher incidence of adenoma compared with metastasis in their series than this study [13]. The uptake in pituitary region of their study group was not significantly higher compared with this study group.

According to the results of this study, the incidental FDG uptake of the sellar region might be a consequence of several reasons including the metastasis of surrounding structures or pituitary gland adenoma. However, this finding does not have influence on the patient's treatment or disease management.

\section{Executive summary}

- The etiology of the incidental fluorodeoxyglucose uptake of the sellar region may be metastasis, adenoma or one of several other lesions.

- However, the metastatic involvement of the sellar region frequently presents with other metastatic sites elsewhere in the body.

- The number of metastatic lesions present in this region was shown to be higher in this study group.

- This finding suggests that the metastatic lesions might be higher due to the specific features of the study group.

- The standardized uptake value levels of the metastatic and pituitary tumors might be similar.

- This finding is unlikely to influence patient management. 
Financial \& competing interests disclosure: None.

The authors have no relevant affiliations or financial involvement with any organization or entity with a financial interest in or financial conflict with the subject matter or materials discussed in the manuscript. This includes employment, consultancies, honoraria, stock ownership or options, expert testimony, grants or patents received or pending, or royalties.

No writing assistance was utilized in the production of this manuscript.

Informed consent disclosure

The authors state that they have obtained appropriate institutional review board approval or have followed the principles outlined in the Declaration of Helsinki for all human or animal experimental investigations. In addition, for investigations involving human subjects, informed consent has been obtained from the participants involved. The authors state that they have obtained verbal and written informed consent from the patient/patients for the inclusion of their medical and treatment history within this research article.

\section{Open access}

This work is licensed under the Attribution-NonCommercial-NoDerivatives 4.0 Unported License. To view a copy of this license, visit http://creativecommons.org/licenses/by-nc-nd/4.0/

\section{References}

Papers of special note have been highlighted as: $\bullet$ of interest; $\bullet \bullet$ of considerable interest

1. Hyun SH, Choi JY, Lee KH, Choe YS, Kim BT. Incidental focal F-FDG uptake in the pituitary gland: clinical significance and differential diagnostic criteria. J. Nucl. Med. 52(4), 547-550 (2011).

- Of interest: similar article with this one.

2. Ezzat S, Asa SL, Cloudwell WT et al. The prevalence of pituitary adenomas: a systematic review. Cancer 101(3), 613-619 (2004).

3. Alzahrani AS, Farhat R, Al-Arifi A, Al-Kahtani N, Kanaan I, Abouized M. The diagnostic value of fused positron emission tomography/computed tomography in the localization of adrenocorticotropin-secreting pituitary adenoma in Cushing's disease. Pituitary 12(4), 309-314 (2009).

4. De Souza B, Brunetti A, Fulham MJ et al. Pituitary microadenomas: a PET study. Radiology 177(1), 39-44 (1990).

5. Soussan M, Wartski M, Ezra J, Glaisner S, Pecking AP, Alberini JL. Non-Hodgkin lymphoma localization in the pituitary gland: diagnosis by FDG-PET/CT. Clin. Nucl. Med. 33(2), 111-112 (2008).

6. Jeong SY, Lee SW, Lee HJ et al. Incidental pituitary uptake on whole-body ${ }^{18} \mathrm{~F}-\mathrm{FDG}$ PET/CT: a multicenter study. Eur. J. Nucl. Med. Mol. Imaging 37(12), 2334-2343 (2010).

•. Of considerable interest: multicenter and similar article.

7. Mukherjee A, Dhull VS, Karunanithi S, Shahrma P, Durgapal P, Kumar R. Pineal gland involvement in Erdheim-Chester disease detected on ${ }^{18}$ F-FDG PET-CT imaging: a case report and review of literature. Clin. Imaging 38(3), 367-371 (2014).

8. Van der Hiel B, Blank CU, Haanen JBAG, Stokkel MPM. Detection of early onset of hypophysitis by ${ }^{18}$ F-FDG PET-CT in a patient with advanced stage melanoma treated with ipilimumab. Clin. Nucl. Med. 38(4), e182-184 (2013).

9. Agarwal KK, Sharma P, Singla S, Suman S, Bal C, Kumar R. A rare case of non-small cell lung cancer metastasizing to the pituitary gland detection with 18 F-FDG PET-CT. Clin. Nucl. Med. 39(5), 318-319 (2014).

10. Burger PC, Scheithauer BW. Tumors of the central nervous system. In: Atlas of Tumor Pathology (3rd Series). Peter C (Ed). Armed Forces Institute of Pathology, DC, USA (1994).

11. Seok H, Lee EY, Yang WI et al. Analysis of 18 F-fluorodeoxyglucose positron emission tomography findings in patients with pituitary lesions. Korean J. Intern. Med. 28(1), 81-88 (2013).

- Of interest: important analysis of sellar lesions by fluorodeoxyglucose positron emission tomography-computed tomography.

12. Bergstrom M, Muhr C, Lundberg PO, Langstrom B. PET as a tool in the clinical evaluation of pituitary adenomas. J. Nucl. Med. 32(4), 610-615 (1991).

13. Ju H, Zhou J, Pan Y, Zhang LV, Zhang Y. Evaluation of pituitary uptake incidentally identified on ${ }^{18}$ F-FDG PET/CT scan. Oncotarget 33(33), 55544-55549 (2017).

14. Salvatore B, D'Amico D, Fonti R. Metastasis to the sellar/suprasellar region in a patient with endometrial carcinoma detected by 18 F-FDG PET/CT. Clin. Nucl. Med. 43(5), 363-364 (2018).

15. Budak ES, Yıldırım Ş, Yıldız S, Öner AO, Gündüz Ş. Two uncommon sites of metastasis: breast and hypophysis metastases of head and neck adenoid cystic carcinoma detected by FDG PET/CT. Mol. Imaging Radioanucl. Ther. 26(3), 120-123 (2017).

16. Kawamata T, Harashima S, Kubo O, Hori T. Intracellar remote metastasis from adenoid cystic carcinoma of parotid gland: case report. Endocr. J. 53(5), 659-663 (2006). 
17. Hughes DJ, Retzlaff A, Sims J et al. Adenoid cystic carcinoma metastatic to the pituitary: a case report and discussion of potential diagnostic value of magnetic resonance elastography in pituitary tumors. World Neurosurg. 91, 669.e11-669.e14 (2016).

18. Albano D, Bosio G, Bertagna F. Incidental pituitary adenoma detected by ${ }^{18} \mathrm{~F} F D G$ PET/CT and ${ }^{18} \mathrm{~F}$-choline PET/CT in the same patient. Rev. Esp. Med. Nucl. Imagen. Mol. 37(4), 250-252 (2018).

19. Feng Z, He D, Mao Z et al. Utility of $11 \mathrm{C}$-methionine and ${ }^{18} \mathrm{~F}$-FDG PET/CT in patients with functioning pituitary adenomas. Clin. Nucl. Med. 41(3), e130-e134 (2016). 